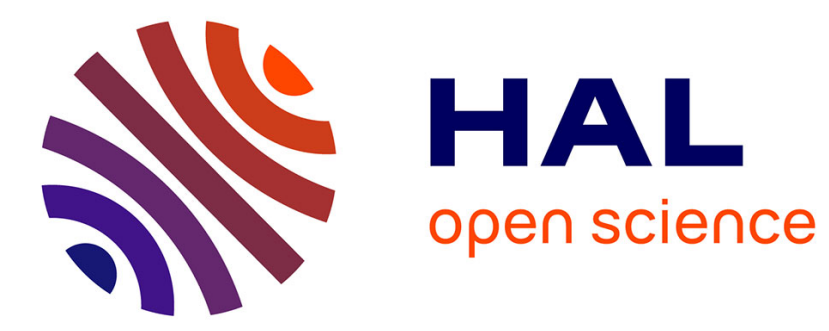

\title{
Optical constants of Pluto tholins
}

Lora Jovanovic, Thomas Gautier, Laurent Broch, Marie Fayolle, Eric Quirico, Tanguy Bertrand, Luc Johann, Aotmane En Naciri, Nathalie Carrasco

\section{To cite this version:}

Lora Jovanovic, Thomas Gautier, Laurent Broch, Marie Fayolle, Eric Quirico, et al.. Optical constants of Pluto tholins. Europlanet Science Congress 2020, Sep 2020, Virtual Meeting, Germany. pp.EPSC2020-707. insu-02925183

\section{HAL Id: insu-02925183 \\ https://hal-insu.archives-ouvertes.fr/insu-02925183}

Submitted on 28 Aug 2020

HAL is a multi-disciplinary open access archive for the deposit and dissemination of scientific research documents, whether they are published or not. The documents may come from teaching and research institutions in France or abroad, or from public or private research centers.
L'archive ouverte pluridisciplinaire HAL, est destinée au dépôt et à la diffusion de documents scientifiques de niveau recherche, publiés ou non, émanant des établissements d'enseignement et de recherche français ou étrangers, des laboratoires publics ou privés. 


\section{Optical constants of Pluto tholins}

Lora Jovanovic $^{1}$, Thomas Gautier ${ }^{1}$, Laurent Broch ${ }^{2}$, Marie Fayolle ${ }^{3,4}$, Eric Quirico ${ }^{3}$, Tanguy Bertrand $^{5}$, Luc Johann ${ }^{2}$, Aotmane En Naciri ${ }^{2}$, and Nathalie Carrasco ${ }^{1}$

${ }^{1}$ Université Paris-Saclay, UVSQ, CNRS, Sorbonne Université, LATMOS/IPSL, Guyancourt, France (lora.jovanovic@latmos.ipsl.fr)

${ }^{2}$ Université de Lorraine, LCP-A2MC, Metz, France

${ }^{3}$ Université Grenoble Alpes, CNRS, IPAG, Grenoble, France

${ }^{4}$ Delft University of Technology, The Netherlands

${ }^{5}$ NASA Ames Research Center, Moffett Field, CA 94035, USA

\section{Introduction}

On July $14^{\text {th }}, 2015$, the New Horizons spacecraft flew by Pluto and revealed the presence of aerosols in the atmosphere $[1,2,3]$ and a curiously dark reddish equatorial region named Cthulhu $[1,4]$. These photochemical aerosols, extending at more than $350 \mathrm{~km}$ of altitude $[2,3,5]$, may affect Pluto atmospheric chemistry and climate $[6,7]$. Furthermore, it was suggested that these aerosols sediment to constitute the non-icy dark material on the surface of Pluto [4,8]. To interpret the data provided by New Horizons, the atmospheric (e.g. [7]) and surface models (e.g. [4,9]) have so far used the optical constants determined for Titan tholins. Nevertheless, since optical constants strongly depend on the chemical composition of the materials [10], and as Pluto tholins differ chemically from those of Titan [11], Pluto aerosol analogues were synthesized in laboratory and their optical constants were determined by spectroscopic ellipsometry.

\section{Experimental setup and analyses protocol}

\section{- Synthesis of Pluto tholins}

We used the PAMPRE experimental setup [12] (LATMOS, France) to synthesize Pluto tholins as thin films onto silicon wafers. For this study, the gas mixture injected into the reactor was composed of variable proportions of $\mathrm{N}_{2}$ and $\mathrm{CH}_{4}$, with $500 \mathrm{ppm}$ of $\mathrm{CO}[5,13]$, to simulate photochemical aerosols formed at different altitudes on Pluto (Table 1). The experiments were conducted at a pressure of $0.9 \pm 0.1$ mbar and at ambient temperature.

Table 1: Types of Pluto tholins analyzed in this study

Composition of the gas mixture Corresponding altitude on PlutoName of the sample [5]

99.5\% $\mathrm{N}_{2}: 0.5 \% \mathrm{CH}_{4}: 500 \mathrm{ppm}<350 \mathrm{~km} \quad \mathrm{P}_{\mathrm{H}}$

$\mathrm{CO}$

$99 \% \mathrm{~N}_{2}: 1 \% \mathrm{CH}_{4}: 500 \mathrm{ppm} \mathrm{CO} 400 \mathrm{~km}$

$95 \% \mathrm{~N}_{2}: 5 \% \mathrm{CH}_{4}: 500 \mathrm{ppm} \mathrm{CO} 600 \mathrm{~km}$

$\mathrm{P}_{400}$

$P_{600}$ 


\section{- Spectroscopic ellipsometry}

We used the UVISEL (Horiba Jobin Yvon) spectroscopic ellipsometer to analyze Pluto tholins thin films. Spectroscopic ellipsometry is a technique measuring the changes in the polarization state between incident and reflected light on the sample, as a function of wavelength. DeltaPsi ${ }^{\circledR}$ software was used to fit the ellipsometric data. More precisely, a modified Tauc-Lorentz dispersion model determined the thicknesses of the thin films, and a wavelength-by-wavelength inversion method was used to retrieve the refractive indices $n$ (Fig. 1) and the absorption coefficients $k$ (Fig. 2), from 270 to $2100 \mathrm{~nm}$.

\section{Optical constants of Pluto tholins from UV to near-IR}

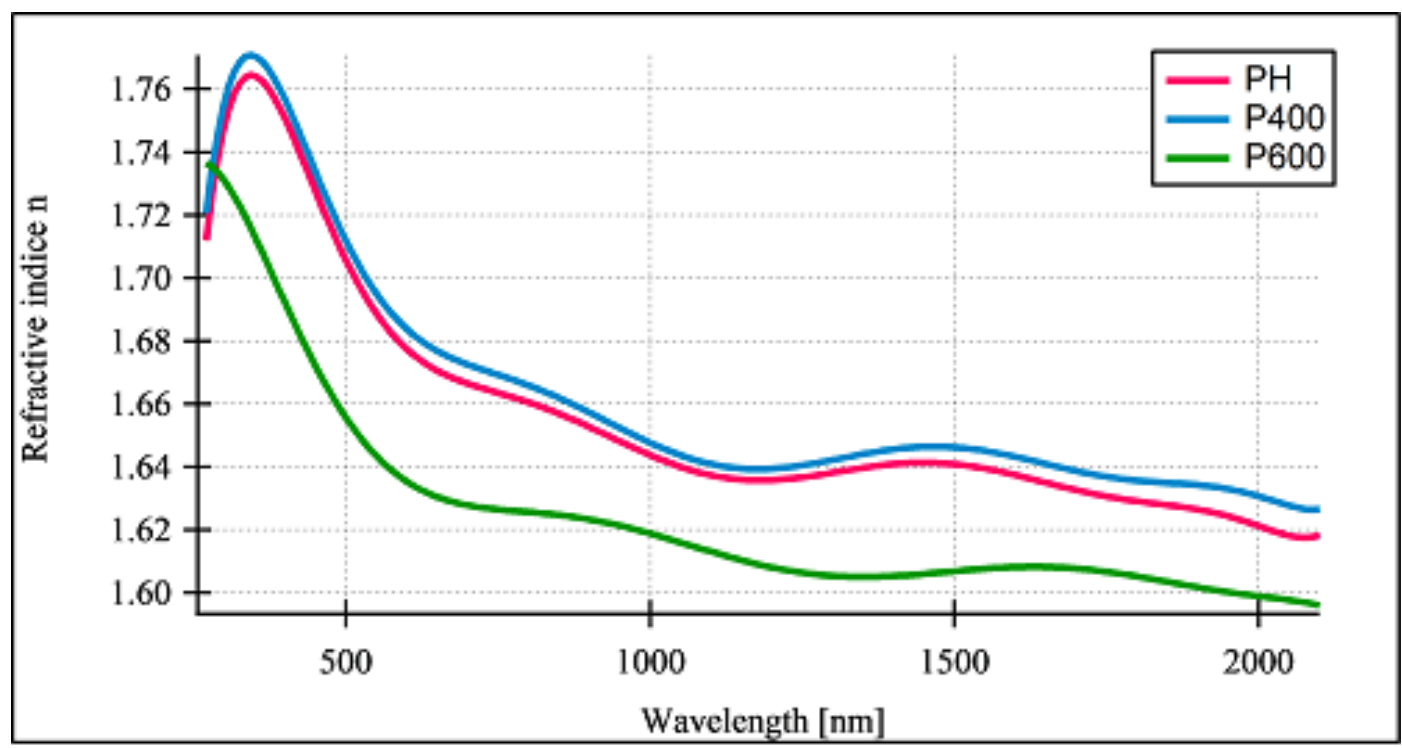

Fig. 1: Refractive indices $n$ of Pluto tholins determined by spectroscopic ellipsometry 




\section{Fig. 2: Absorption coefficients $k$ of Pluto tholins determined by spectroscopic ellipsometry}

Our study shows: (1) the refractive indices $n$ of Pluto tholins vary from 1.60 to 1.77 , and such $n$ -values can correspond to organic polymers [14]; (2) a strong absorption of UV and Visible radiation by Pluto tholins, due to their $\mathrm{N}$ - and O-bearing molecules $[15,16,17]$; (3) a lower absorption in the near-IR with $k$-values of a few $10^{-3} ;$ (4) a dependency of $n$ and $k$ indices to the altitude of aerosols formation, with especially higher $n$ - and $k$-values in the UV-Vis spectral range for Pluto low-altitude aerosols $\left(\mathrm{P}_{\mathrm{H}}\right.$ and $\left.\mathrm{P}_{400}\right)$.

\section{Discussion and Conclusion}

Due to higher $n$-values for the samples $P_{H}$ and $P_{400}$, compared to the $P_{600}$ sample, we can suppose that aerosols formed in Pluto's lower atmosphere ( $\leq 400 \mathrm{~km}$ of altitude) will differently scatter the light compared to aerosols formed at higher altitudes ( $>400 \mathrm{~km}$ of altitude) [18], and thus differently affect the photon flux reaching the lower atmosphere and the surface. The strong absorption below $600 \mathrm{~nm}$ is likely due to the presence of $\mathrm{N}$ - and O-bearing molecules with lone pair, $\mathrm{N}$ - and O-containing polycyclic aromatic compounds and unsaturated molecules with extensive conjugated multiple bonds [14-17]. Since the nitrogen and oxygen content is higher in low-altitude tholins [11], their $k$ indices are higher in the UV-Vis wavelength range. We can thus suppose that in Pluto's atmosphere the aerosols formed at different altitudes will differently absorb the photon flux and differently affect Pluto atmospheric and surface radiative transfer [18].

As Pluto tholins are chemically different from Titan's [11], we propose a new set of optical constants to update Pluto atmospheric and surface models that were hitherto based on the optical constants of Titan tholins.

\section{Acknowledgements}

We are grateful to the European Research Council Starting Grant PrimChem for funding this work (grant agreement $n^{\circ}$ 636829).

\section{References}

[1] Stern S. A. et al., Science, Vol. 350, aad1815, 2015.

[2] Gladstone G. R. et al., Science, Vol. 351, aad8866, 2016.

[3] Cheng A. F. et al., Icarus, Vol. 290, pp. 112-133, 2017. 
[4] Grundy W. M. et al., Icarus, Vol. 314, pp. 232-245, 2018.

[5] Young L. A. et al., Icarus, Vol. 300, pp. 174-199, 2018.

[6] Luspay-Kuti A. et al., Monthly Notices of the Royal Astronomical Society, Vol. 472, pp. 104-117, 2017.

[7] Zhang X. et al., Nature, Vol. 551, pp. 352-355, 2017.

[8] Cruikshank D. P. et al., Icarus, Vol. 246, pp. 82-92, 2015.

[9] Protopapa S. et al., Astronomical Journal, Vol. 159, pp. 159-174, 2020.

[10] Brassé C. et al., Planetary and Space Science, Vol. 109-110, pp. 159-174, 2015.

[11] Jovanović L. et al., Icarus, Vol. 346, 113774, 2020.

[12] Szopa C. et al., Planetary and Space Science, Vol. 54, pp. 394-404, 2006.

[13] Lellouch E. et al., Icarus, Vol. 286, pp. 289-307, 2017.

[14] van Krevelen D. W. and te Nijenhuis K.: Chapter 10: Optical Properties, in Properties of Polymers, pp. 287-320, 2009.

[15] Rao C. N. R.: Ultraviolet and visible spectroscopy, 1975.

[16] Imanaka H. et al., Icarus, Vol. 168, pp. 344-366, 2004.

[17] Lambe A. T. et al., Environmental Science \& Technology, Vol. 47, pp. 6349-6357, 2013.

[18] Boucher O.: Atmospheric aerosols - Properties and climate impacts, 2015. 